Research Article

\title{
The Effect of Grapefruit Juice on the Pharmacokinetics of Tadalafil in Rats
}

\author{
Xiuwei Shen (D), Fan Chen, Fengwei Wang, Peng Huang (D), and Wenchao Luo \\ Ruian People's Hospital, The Third Affiliated Hospital of Wenzhou Medical University, 325000 Wenzhou, China \\ Correspondence should be addressed to Peng Huang; hp2014032@126.com and Wenchao Luo; luowenchao6702@163.com
}

Received 8 July 2019; Revised 9 December 2019; Accepted 30 December 2019; Published 25 January 2020

Academic Editor: Aijun Wang

Copyright ( 2020 Xiuwei Shen et al. This is an open access article distributed under the Creative Commons Attribution License, which permits unrestricted use, distribution, and reproduction in any medium, provided the original work is properly cited.

We developed and validated a novel, sensitive, selective, and inexpensive high-performance liquid chromatography (HPLC) method for the determination of tadalafil in rats plasma and to investigate the effect of grapefruit juice on the pharmacokinetics of tadalafil in rats. The ZORBAX Eclipse XDB-C18 $(4.6 \times 150 \mathrm{~mm}, 5 \mu \mathrm{m})$ chromatography column can be used to separate tadalafil and carbamazepine (internal standard, IS). A mixture of acetonitrile- $0.2 \%$ trifluoroacetic acid-water $(48: 10: 42$, V/V/V) was used as the mobile phase with a flow rate of $1.0 \mathrm{~mL} / \mathrm{min}$. The column temperature was set at $35.0^{\circ} \mathrm{C}$. The detection wavelength was set at $286 \mathrm{~nm}$. The tadalafil was extracted by ethyl acetate from plasma at the alkaline condition. 12 healthy male Sprague-Dawley (SD) rats were randomly divided into two groups, Group A (experimental group, received grapefruit juice $5 \mathrm{~mL} / \mathrm{kg}$ for 7 days) and Group B (control group, received normal saline for 7 days). All the rats were given a single dose of tadalafil ( $5 \mathrm{mg} / \mathrm{kg}$ ) after the last administration. The main pharmacokinetic parameters were calculated by DAS 2.0 software. Under the conditions of this experiment, the plasma concentrations of tadalafil in the range of $10-2000 \mathrm{ng} / \mathrm{ml}$ had a good linear relationship. The intra- and interday precision for tadalafil in plasma were less than $15 \%$, and the relative recovery rate was good at low, medium, and high QC levels. The $C_{\max }$ of tadalafil in the control group and the experimental group was $(725.89 \pm 161.59) \mathrm{ng} / \mathrm{mL}$ and $(1271.60 \pm 179.31)$ $\mathrm{ng} / \mathrm{mL}, t_{1 / 2}$ was $(9.28 \pm 2.07) \mathrm{h}$ and $(11.70 \pm 1.47) \mathrm{h}, \mathrm{AUC}_{(0-t)}$ was $(7399.61 \pm 696.85) \mathrm{ng} \cdot \mathrm{h} / \mathrm{mL}$ and $(9586.52 \pm 2048.81) \mathrm{ng} \cdot \mathrm{h} / \mathrm{mL}$, and $\mathrm{AUC}_{(0-\infty)}$ was $(7995.50 \pm 707.23) \mathrm{ng} \cdot \mathrm{h} / \mathrm{mL}$ and $(10639.43 \pm 2235.94) \mathrm{ng} \cdot \mathrm{h} / \mathrm{mL}$, respectively. Results show that the $C_{\max }$ of tadalafil in group A was $75.17 \%$ higher than that in group B, the $\mathrm{Vz} / \mathrm{F}$ was also reduced, and the $t_{1 / 2}$ was increased by $2.42 \mathrm{~h}$. The developed HPLC-DAD method for the determination of tadalafil in rats plasma was accurate, reproducible, specific, and it was found to be suitable for the pharmacokinetics of tadalafil and food-drug interactions. Grapefruit juice can inhibit the metabolism of tadalafil and increase the exposure of tadalafil in rats.

\section{Introduction}

Tadalafil is a competitive inhibitor of PDE-5, which prevents the degradation of cyclic guanosine monophosphate (cGMP), leading to an increase in cGMP and induction of corpus cavernosum smooth muscle relaxation, thereby increasing blood flow and causing penile erection [1, 2]. Tadalafil has been approved for pulmonary arterial hypertension (PAH) [3], erectile dysfunction (ED) [4], benign prostatic hyperplasia (BHP) [5], the lower urinary tract symptoms (LUTS) [6], and so on. Tadalafil was approved for the treatment of ED in 2009.

Tadalafil was rapidly absorbed after oral administration and reaches $C_{\max } 2$ hours after taking the drug. The absorption rate and degree of tadalafil are not affected by food, so this product can be taken with or without food. Tadalafil is metabolized in the body primarily to inactive catechol metabolites by CYP3A4. Tadalafil is mainly excreted by feces, and about $1 / 3$ of the metabolized drugs are excreted from the urine [7-9].

Tadalafil is mainly metabolized by CYP3A4. Studies have shown that some drugs inhibit CYP3A4 and increase exposure to tadalafil. Ketoconazole $(400 \mathrm{mg} / \mathrm{d})$ is a potent inhibitor of CYP3A4, which increases the AUC and $C_{\max }$ of tadalafil $(20 \mathrm{mg} / \mathrm{d})$ by $312 \%$ and $22 \%$, respectively. Ketoconazole $(200 \mathrm{mg} / \mathrm{d})$ increased the AUC and $C_{\max }$ of tadalafil $(10 \mathrm{mg} / \mathrm{d})$ by $107 \%$ and $15 \%$, respectively, compared to the single dose of tadalafil $(10 \mathrm{mg})$. Although there are no 
specific interaction studies, other CYP3A4 inhibitors, such as erythromycin, itraconazole, and grapefruit juice may also increase the exposure levels of tadalafil $[10,11]$.

Grapefruit belongs to the family Rutaceae owing to several bioactive substances, such as flavonoids, carotenoids, coumarins, and organic acids, with a variety of healthpromoting properties, such as anti-inflammatory, anticancer, and weight loss [12-14]. Flavonoids are seen as the most important bioactive components present in grapefruit. It has the functions of antioxidants, free radical elimination, tumor prevention, and cancer cell proliferation [15]. Numerous studies have shown that furocoumarin in grapefruit interacts with drugs by interfering with tactile and intestinal enzymes cytochrome P450 [16]. Studies have shown that both food and grapefruit juice can increase the exposure of blonanserin and $\mathrm{N}$-desethyl blonanserin. Grapefruit juice improves bioavailability and may have reduced systemic clearance of blonanserin. The obvious explanation is that grapefruit juice can inhibit the activity of CYP3A4 in the intestinal [17].

Food-drug interactions can produce negative effects in the safety and efficacy of drug therapy, as well as in the nutritional status of the patient [18]. Tadalafil is metabolized by CYP3A4 in the body, and grapefruit juice is an inhibitor of CYP3A4. It may affect the metabolism of tadalafil in the body. A method for the determination of the concentration of tadalafil in rat plasma by HPLC was established. By measuring the concentration of tadalafil in the plasma and studying the effect of grapefruit juice on the pharmacokinetics of tadalafil in rats, it can provide a theoretical basis for food-drug interaction.

\section{Experimental}

2.1. Chemicals Materials. Tadalafil (purity $>98 \%$, CAS: 171596-29-5) and carbamazepine (CBZ, purity $>98 \%$, CAS: 100142-199503) were provided from Sigma (St. Louis, MO, USA). Tadalafil tablets (5 mg, CAS: C791509) were provided from Lilly del Caribe, Inc. Grapefruit juice (purity 100\%) was obtained from the fresh fruit juice industry Kunshan co. LTD. (Kun Shang, China). Methanol and acetonitrile were of HPLC grade and were provided by Merck Company (Darmstadt, Germany).

2.2. Instrumentation and Conditions. The analyses were performed using an Agilent 1100 liquid chromatographic system equipped with a G1379A vacuum degasser, a G1311A quaternary pump, a G1316A column oven, a G1313A autosampler, and G1315B DAD detector.

Samples were separated on a ZORBAX Eclipse XDB-C18 $(4.6 \times 150 \mathrm{~mm}, 5 \mu \mathrm{m}$, Agilent, USA $)$ and XDB-C18 protection column at $35^{\circ} \mathrm{C}$. The mobile phase consisted of acetonitrile- $0.2 \%$ trifluoroacetic acid-water $(48: 10: 42)$. All compounds were detected at an optimum wavelength of $286 \mathrm{~nm}$, and the flow rate of the mobile phase was $1.0 \mathrm{~mL} /$ $\min$.

2.3. Preparation of Standard and Quality Control (QC) Samples. A stock solution of $1 \mathrm{mg} / \mathrm{mL}$ was prepared by weighing $10 \mathrm{mg}$ of tadalafil and dissolving it in $10 \mathrm{ml}$ of methanol. The standard application solution was diluted with methanol to the concentrations of $100 \mu \mathrm{g} / \mathrm{mL}, 10 \mu \mathrm{g} /$ $\mathrm{mL}$, and $1 \mu \mathrm{g} / \mathrm{mL}$. A stock solution of $1 \mathrm{mg} / \mathrm{mL}$ was prepared by weighing $1 \mathrm{mg}$ of CBZ and dissolving it in $1 \mathrm{ml}$ of methanol and then diluting it to $4.0 \mu \mathrm{g} / \mathrm{mL}$ standard solution. All of the solutions were stored in a refrigerator at $4^{\circ} \mathrm{C}$. Calibration curve standards were prepared by adding appropriate amounts of the working solutions in blank rat plasma. The final concentrations of tadalafil were $10,25,50$, $100,250,500,1000$, and $2000 \mathrm{ng} / \mathrm{mL}$, respectively, and the concentration of IS was $400 \mathrm{ng} / \mathrm{mL}$ in rat plasma. The preparation of QC samples was the same, with three levels of plasma concentrations $(25,500$, and $1500 \mathrm{ng} / \mathrm{mL})$.

2.4. Sample Preparation. Before the analysis, the plasma samples were thawed to room temperature. In a $2 \mathrm{~mL} E P$ tube, an aliquot of $20 \mu \mathrm{L}$ of the IS working solution $(4.0 \mu \mathrm{g} /$ $\mathrm{mL})$ and $200 \mu \mathrm{L}$ of $\mathrm{NaOH}(1 \mathrm{~mol} / \mathrm{L})$ were added to $200 \mu \mathrm{L}$ of collected plasma sample followed by the addition of $1.0 \mathrm{~mL}$ ethyl acetate. The tubes were vortex mixed for $1.0 \mathrm{~min}$ and centrifuged at $3,000 \mathrm{rpm}$ for $10 \mathrm{~min}$ at $4^{\circ} \mathrm{C}$. Then, an aliquot of $900 \mu \mathrm{L}$ supernatant organic layer was transferred into a $1.5 \mathrm{~mL}$ EP tube and dried under a nitrogen stream at $40^{\circ} \mathrm{C}$. The dried residue was reconstituted in $100 \mu \mathrm{L}$ of a mobile phase and a $10 \mu \mathrm{L}$ aliquot was injected into the HPLC system for the analysis.

2.5. Method Validation. To evaluate the selectivity of the method, the blank rats plasma and blank plasma spiked tadalafil and CBZ were analyzed. Calibration curves were constructed and validated by analyzing spiked calibration samples for three days in a row. The peak area ratio of tadalafil and CBZ was $y$, and the ratio of the concentration of tadalafil to CBZ was $x$, and standard curves were fitted by weighted $\left(1 / \chi^{2}\right)$ least squares linear regression in the concentration of $10-2000 \mathrm{ng} / \mathrm{mL}$.

Accuracy and precision were assessed by the determination of QC samples at three concentration levels $(25,500$, and $1500 \mathrm{ng} / \mathrm{mL}$ ) in six replicates. On the same day, the intraprecisions were calculated, and the interprecisions were calculated by continuous measurement within 3 days.

The recoveries of tadalafil at three QC levels $(25,500$, and $1500 \mathrm{ng} / \mathrm{mL}, n=6$ ) were determined by comparing the peak area of the analytes in the sample with the analyte added before extraction and the sample with the corresponding solution after extraction. The RSD of each concentration recovery should be within $15 \%$.

The stabilities of tadalafil in rat plasma were tested by analyzing six replicates of plasma samples at three concentration levels $(25,500$, and $1500 \mathrm{ng} / \mathrm{mL})$ in different conditions. The short-term stability was determined after the exposure of the spiked samples at room temperature for $24 \mathrm{~h}$. The freeze-thaw stability was evaluated after three complete freeze-thaw cycles $\left(-20^{\circ} \mathrm{C}\right)$ on consecutive days. The long-term stability was assessed after storage of the standard spiked plasma samples at $-20^{\circ} \mathrm{C}$ for 21 days. 
2.6. Animals. Male Sprague-Dawley rats with body weights of $220 \pm 20 \mathrm{~g}$ were obtained from Henan University of Science and Technology. The rats were adapted to the new environment for 7 days in laboratory conditions. Necessary approval from the Institutional Animal Ethics Committee was obtained to carry out the experiments.

2.7. Study Design. Twelve Sprague-Dawley male rats were randomly divided into 2 groups: Group A (experimental group, long-term administered with $5 \mathrm{ml} / \mathrm{kg}$ grapefruit juice for 7 days) and Group B (control group, the control group received normal saline for 7 days). All the rats were given a single dose of tadalafil with a concentration of $5 \mathrm{mg} / \mathrm{kg}$. All the blood samples $(0.3 \mathrm{~mL})$ were collected from the tail-vein into heparinized $1.5 \mathrm{~mL}$ polythene tubes at $0.33,0.67,1,1.5$, $2,3,4,6,8,12,24,36$ and $48 \mathrm{~h}$ after tadalafil oral administration. The samples were immediately centrifuged at $10000 \mathrm{rmp}$ for $10 \mathrm{~min}$. The plasma obtained $(200 \mu \mathrm{L})$ was stored at $-20^{\circ} \mathrm{C}$ until analysis.

2.8. Statistical Analysis. The mean and standard deviation (SD) were used for the results. The compartmental analysis was used to calculate the pharmacokinetic parameters by DAS 2.0 (Drug and statistics) software. The statistical analyses were evaluated by unpaired $t$-test (SPSS 19.0, Chicago, IL). A value of $p<0.05$ was considered to be statistically significant.

\section{Results}

3.1. Sensitivity. Under the experimental conditions described, tadalafil and CBZ were well separated from endogenous materials. Representative chromatograms of a blank plasma sample, a plasma sample spiked with tadalafil and CBZ, and a rat sample obtained $1.5 \mathrm{~h}$ after oral administration of tadalafil were shown in Figure 1. The retention time of tadalafil and CBZ were 6.41 and $5.44 \mathrm{~min}$, respectively.

3.2. The Linearity of Calibration Curve. The linear regressions of the peak area ratios versus concentrations were fitted over the concentration range of $10-2000 \mathrm{ng} / \mathrm{mL}$. The typical equations of the calibration curve were as follows: $y=0.0124 x+0.0638, r=0.999 .8$. The LLOQ of tadalafil in rat plasma was $10 \mathrm{ng} / \mathrm{mL}$.

3.3. Precision and Accuracy. The precision of the method was evaluated by calculating RSD for QCs at three concentration levels $(25,500$, and $1500 \mathrm{ng} / \mathrm{mL})$ over three validation days. The intraday RSDs were $4.69 \%, 3.27 \%$, and $4.54 \%$ and the interday RSDs were $8.28 \%, 6.29 \%$, and $4.86 \%$, respectively, at three concentrations.

The accuracy of the method ranged from $-2.00 \%$ to $3.88 \%$ for tadalafil at three QC levels. Assay performance data were presented in Table 1 . The results demonstrated that the values were within the acceptable range and the method was accurate and precise.
3.4. Recovery. Mean extraction recoveries of tadalafil in rat plasma were $(78.16 \pm 3.14) \%, \quad(81.38 \pm 1.93) \%$, and $(80.56 \pm 1.68) \%(n=6)$ at the concentrations of 25,500 , and $1500 \mathrm{ng} / \mathrm{mL}$, respectively (Table 2).

3.5. Stability. The RSDs of the three quality control plasma samples $(25,500$, and $1500 \mathrm{ng} / \mathrm{mL})$ with spiked tadalafil were less than $10 \%$, and tadalafil has shown good stability in plasma for $24 \mathrm{~h}$ at room temperature, during three freezethaw cycles, and for 21 days at $-20^{\circ} \mathrm{C}$ (Table 3).

3.6. Effect of Grapefruit Juice on the Pharmacokinetic of Tadalafil. Figure 2 reveals the mean plasma concentration time profiles of tadalafil after oral administration of tadalafil $(5 \mathrm{mg} / \mathrm{kg})$ in the different treatment group. The corresponding pharmacokinetic parameters are revealed in Table 4. As shown in Table 4 and Figure 2, grapefruit juice significantly altered the pharmacokinetic parameters of tadalafil. Compared with group $\mathrm{A}$, the $C_{\max }$ of tadalafil was significantly increased by $57.4 \%$ by grapefruit juice. Moreover, the $\mathrm{AUC}_{(0-\infty)}$ of tadalafil was increased by $29.55 \%$. In addition, the $\mathrm{Vz} / \mathrm{F}$ was also reduced, and the $t_{1 / 2}$ was increased by $2.42 \mathrm{~h}$. According to the data, it showed that grapefruit juice has a significant influence on the pharmacokinetics of tadalafil in rats.

\section{Discussion}

Food-drug interactions can produce negative effects in the safety and efficacy of drug therapy, as well as in the nutritional status of the patient [18]. The actual proportion of adverse drug reactions due to food-drug interactions is not known and, unfortunately, only when a serious adverse drug reaction follows a food-drug interaction does the matter receive significant attention [19].

Tadalafil is the substrate of CYP3A4, which is mainly metabolized by CYP3A4. Studies have shown that drugs that inhibit CYP3A4 can increase the exposure levels of tadalafil. Rifampicin (600 mg/day) is a CYP3A4 inducer, which can reduce the AUC and Cmax of tadalafil by $88 \%$ and $46 \%$, respectively, compared with the $10 \mathrm{mg}$ single dose of tadalafil $[10,11]$.

Grapefruit juice is a common inhibitor of CYP3A4 enzyme [20], which can slow down drug metabolism through liver metabolism, resulting in increased drug concentration in the body and increased adverse reactions. As the medications, such as darifenacin, fesoterodine, oxybutynin, and solifenacin, are metabolized in the liver by CYP3A4, their potential to interact with grapefruit juice cannot be neglected $[21,22]$.

In our experiment, we gave grapefruit juice to rats for 7 days, which had sufficient effects on enzymes and proteins in the body of rats. Tadalafil is the substrate of CYP3A4 and is mainly metabolized by CYP3A4. Compared with the control group, the $t_{1 / 2}$ of tadalafil was significantly prolonged in the experimental group. Results show that the $C_{\max }$ of tadalafil in group A (experimental group) was $75 \%$ higher than that in group B (control group). The CLz/F was also reduced, and 


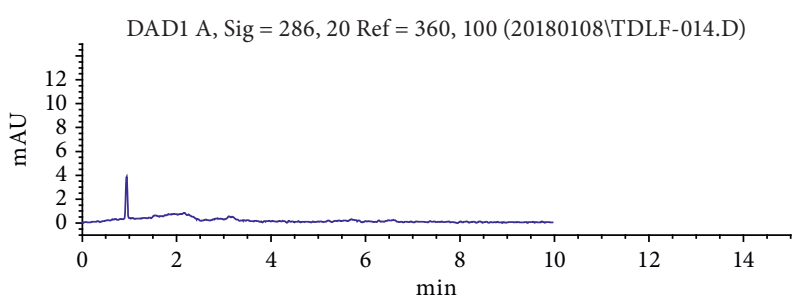

(a)

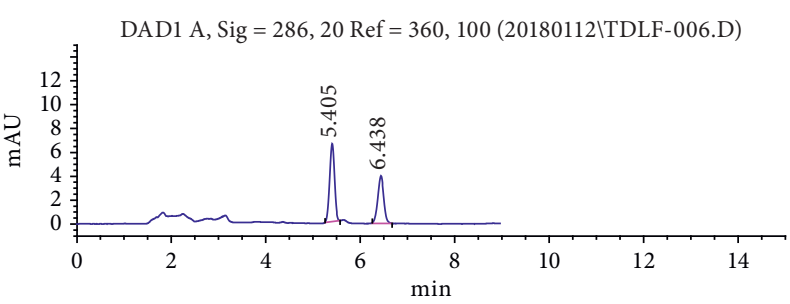

(b)

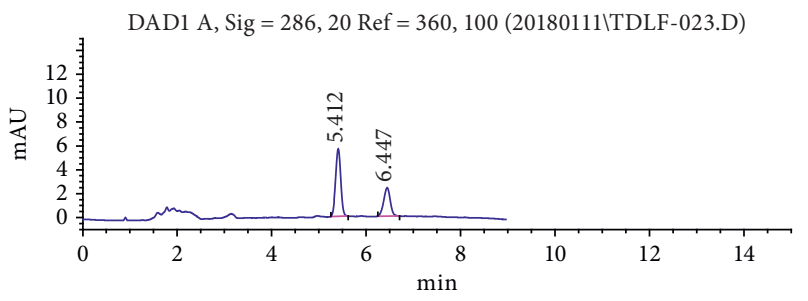

(c)

FIGURE 1: Representative HPLC for tadalafil and CBZ (IS) in rat plasma. (a) Blank plasma sample; (b) blank plasma sample spiked with tadalafil and CBZ; (c) rat plasma sample obtained $1.5 \mathrm{~h}$ after oral administration.

Table 1: Precision and accuracy for tadalafil of QC samples in rat plasma $(n=6)$.

\begin{tabular}{|c|c|c|c|c|c|c|}
\hline \multirow{2}{*}{ Added (ng/mL) } & \multicolumn{3}{|c|}{ Intraday } & \multicolumn{3}{|c|}{ Interday } \\
\hline & Found $(\mathrm{ng} / \mathrm{mL})$ & RSD (\%) & RE (\%) & Found $(\mathrm{ng} / \mathrm{mL})$ & RSD (\%) & $\mathrm{RE}(\%)$ \\
\hline 25 & $25.97 \pm 1.22$ & 4.69 & 3.88 & $24.04 \pm 1.99$ & 8.28 & -2.00 \\
\hline 1000 & $483.99 \pm 15.84$ & 3.27 & 2.50 & $493.97 \pm 31.09$ & 6.29 & 0.30 \\
\hline 1500 & $1479.15 \pm 67.11$ & 4.54 & 1.20 & $1539.65 \pm 74.87$ & 4.86 & -1.53 \\
\hline
\end{tabular}

TABLE 2: Recovery of tadalafil from rat plasma after extraction $(n=6)$.

\begin{tabular}{lccc}
\hline Analytes & Added $(\mathrm{ng} / \mathrm{mL})$ & Recovery $(\%)$ & RSD $(\%)$ \\
\hline \multirow{2}{*}{ Tadalafil } & 25 & $78.91 \pm 2.42$ & 3.07 \\
& 500 & $82.57 \pm 2.32$ & 2.81 \\
\hline \multirow{2}{*}{ IS } & 1500 & $81.21 \pm 2.13$ & 2.63 \\
& 400 & $83.35 \pm 4.13$ & 3.21 \\
\hline
\end{tabular}

TABle 3: Stock solution stability tests for the determination of tadalafil in rat plasma $(n=6)$.

\begin{tabular}{lccc}
\hline $\begin{array}{l}\text { Storage } \\
\text { conditions }\end{array}$ & $\begin{array}{c}\text { Concentration added (ng/ } \\
\mathrm{mL})\end{array}$ & $\begin{array}{c}\text { Tadalafil } \\
\mathrm{RSD} \\
(\%)\end{array}$ & $\begin{array}{c}\mathrm{RE} \\
(\%)\end{array}$ \\
\hline \multirow{3}{*}{ Ambient, 24h } & 25 & 4.19 & 2.3 \\
& 500 & 2.30 & 3.1 \\
& 1500 & 1.12 & 2.7 \\
\hline \multirow{2}{*}{ Three freeze- } & 25 & 2.34 & -2.4 \\
thaw & 500 & 2.17 & 3.7 \\
& 1500 & 1.43 & -5.4 \\
\hline \multirow{2}{*}{$-80^{\circ} \mathrm{C}$, 4 weeks } & 25 & 4.03 & 3.9 \\
& 500 & 2.81 & -2.7 \\
& 1500 & 1.21 & 3.1 \\
\hline
\end{tabular}

the half-life was increased by $2.42 \mathrm{~h}$. In combination with grapefruit juice, the AUC and the half-life of tadalafil were increased, while grapefruit juice increased the exposure of

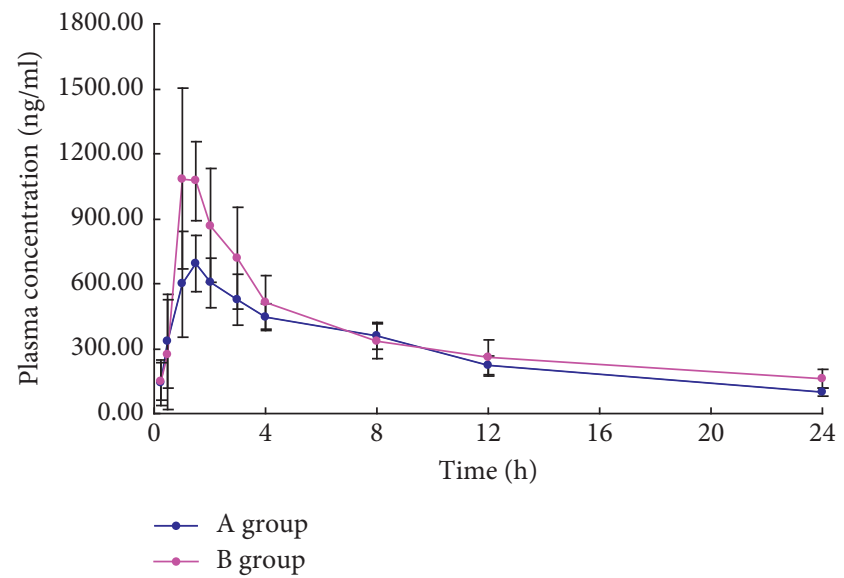

FIgURE 2: Mean plasma concentration time profiles of tadalafil in 2 groups after oral administration of $5 \mathrm{mgkg}$ tadalafil (Means $\pm \mathrm{SD}$, $n=6)$.

tadalafil. These results suggest that grapefruit juice could inhibit the metabolism of tadalafil.

Although there are some differences in metabolism between different species, the results of animal experiments could provide a references for clinical medication. Therefore, when the grapefruit juice and tadalafil would be used together, the drug dose should be adjusted to ensure the efficacy and avoid adverse reactions. Specific medicinal substances, or supplements, consumed with food may 
TABLE 4: The main pharmacokinetic parameters of tadalafil after oral administration of $5 \mathrm{mg} / \mathrm{kg}$ tadalafil in rat plasma (means $\pm \mathrm{SD}$, $n=6)$.

\begin{tabular}{lcc}
\hline Parameters & $\begin{array}{c}\text { Group A } \\
\text { (tadalafil + grapefruit juice) }\end{array}$ & $\begin{array}{c}\text { Group B } \\
\text { (tadalafil) }\end{array}$ \\
\hline$t_{1 / 2}(\mathrm{~h})$ & $11.70 \pm 1.47$ & $9.28 \pm 2.07$ \\
$T_{\max }(\mathrm{h})$ & $1.25 \pm 0.27$ & $1.25 \pm 0.27$ \\
$C_{\max }(\mathrm{ng} / \mathrm{mL})$ & $1271.60 \pm 179.31$ & $725.89 \pm 161.59$ \\
$\mathrm{AUC}_{(0-t)}$ & $9586.52 \pm 2048.81$ & $7399.61 \pm 696.85$ \\
$(\mathrm{ng} \cdot \mathrm{h} / \mathrm{mL})$ & & \\
$\mathrm{AUC}$ & & $7995.50 \pm 707.23$ \\
$(\mathrm{ng} \cdot \mathrm{h} / \mathrm{mL})$ & $10639.43 \pm 2235.94$ & $0.63 \pm 0.06$ \\
$\mathrm{CL}_{\mathrm{z}} / \mathrm{F}(\mathrm{L} / \mathrm{h} / \mathrm{kg})$ & $0.50 \pm 0.14$ & $8.48 \pm 2.25$ \\
$\mathrm{Vd}_{\mathrm{z}} / \mathrm{F}(\mathrm{L} / \mathrm{kg})$ & $8.42 \pm 2.96$ & \\
\hline
\end{tabular}

significantly affect the efficacy and safety of the therapy. Gaps in knowledge on interactions especially with respect to the consequences of food-drug interactions are evident [23].

\section{Conclusions}

The HPLC-DAD method established in this study was used to detect tadalafil in rat plasma. It has high specificity, complete separation, and fast detection time. It was suitable for the pharmacokinetics and food-drug interaction studies of tadalafil. Grapefruit juice could increase the plasma exposure of tadalafil in the body, suggesting that grapefruit juice could inhibit the metabolism of tadalafil. Patients using tadalafil should pay attention to food-drug interactions when drinking grapefruit juice.

\section{Data Availability}

The data used to support the findings of this study are available from the corresponding author upon request.

\section{Conflicts of Interest}

None of the authors has any other conflicts of interest related to this paper.

\section{Authors' Contributions}

Xiuwei Shen and Fan Chen equally contributed to this work.

\section{Acknowledgments}

This study was supported by grants of the Livelihood Projects of Rui'an Science and Technology Bureau, MS2018021.

\section{References}

[1] A. Briganti, A. Salonia, A. Gallina et al., "Drug insight: oral phosphodiesterase type 5 inhibitors for erectile dysfunction," Nature Clinical Practice Urology, vol. 2, no. 5, pp. 239-247, 2005.

[2] A. Tsertsvadze, H. A. Fink, F. Yazdi et al., "Oral phosphodiesterase-5 inhibitors and hormonal treatments for erectile dysfunction: a systematic review and meta-analysis," Annals of Internal Medicine, vol. 151, no. 9, pp. 650-661, 2009.
[3] J. G. Coghlan, N. Galiè, J. A. Barberà et al., "Initial combination therapy with ambrisentan and tadalafil in connective tissue disease-associated pulmonary arterial hypertension (CTD-PAH): subgroup analysis from the AMBITION trial," Annals of the Rheumatic Diseases, vol. 76, no. 7, pp. 12191227, 2017.

[4] G. Li, H. Lan, J. Liang, C. Zhang, and C. Huang, "Efficacy of tadalafil de-escalation in the treatment of psychogenic erectile dysfunction," Urologia Internationalis, vol. 98, no. 2, pp. 205-209, 2016.

[5] T. Amano, C. Earle, T. Imao, Y. Matsumoto, T. Kishikage et al., "Administration of daily $5 \mathrm{mg}$ tadalafl improves endothelial function in patients with benign prostatic hyperplasia," Aging Male, vol. 21, no. 1, pp. 77-82, 2017.

[6] S. W. Kim, N. C. Park, S. W. Lee et al., "Efficacy and safety of a fixed-dose combination therapy of tamsulosin and tadalafl for patients with lower urinary tract symptoms and erectile dysfunction: results of a randomized, double-blinded, activecontrolled trial," The Journal of Sexual Medicine, vol. 14, no. 8, pp. 1018-1027, 2017.

[7] S. L. Washington III and A. W. Shindel, "A once-daily dose of tadalafl for erectile dysfunction: compliance and efficacy," Drug Design, Development and Therapy, vol. 4, pp. 159-171, 2010.

[8] J. Anderson, J. Nawarskas, and A. Henrie, "Clinical utility of tadalafl in the treatment of pulmonary arterial hypertension: an evidence-based review," Core Evidence, vol. 10, pp. 99-109, 2015.

[9] S. T. Forgue, B. E. Patterson, A. W. Bedding et al., "Tadalafil pharmacokinetics in healthy subjects," British Journal of Clinical Pharmacology, vol. 61, no. 3, pp. 280-288, 2006.

[10] C. Loue and M. Tod, "Reliability and extension of quantitative prediction of CYP3A4-mediated drug interactions based on clinical data," The AAPS Journal, vol. 16, no. 6, pp. 1309-1320, 2014.

[11] CIALIS, 2013, http://www.ema.europa.eu/docs/en_GB/document_ library/EPAR__Product_Information/human/001241/ WC500100494.pdf.

[12] E. Madrigal-Bujaidar, L. M. Roaro, K. Garcia-Aguirre, S. Garcia-Medina, and I. Alvarez-Gonzalez, "Grapefruit juice suppresses azoxymethane-induced colon aberrant crypt formation and induces antioxidant capacity in mice," Asian Pacific Journal of Cancer Prevention, vol. 14, no. 11, pp. 6851-6856, 2013.

[13] A. A. Mahgoub, "Grapefruit juice potentiates the anti-inflammatory effects of diclofenac on the carrageenan-induced rat's paw oedema," Pharmacological Research, vol. 45, no. 1, pp. 1-4, 2002.

[14] C. Rostislav, T. Airlia, T. Kevin, M. Hellerstein, J. L. Napoli, and A. Stahl, "Consumption of clarified grapefruit juice ameliorates high-fat diet induced insulin resistance and weight gain in mice," PLoS One, vol. 9, no. 10, Article ID e108408, 2014.

[15] I. Erlund, E. Meririnne, G. Alfthan, and A. Aro, "Plasma kinetics and urinary excretion of flavanones naringenin and hesperetin in humans after ingestion of orange juice and grapefruit juice," The Journal of Nutrition, vol. 131, no. 2, pp. 235-241, 2001.

[16] G. Lianqing, K. Fukuda, T. Ohta et al., "Role of furanocoumarin derivatives on grapefruit juice-mediated inhibition of human CYP3A activity," Drug Metabolism \& Disposition the Biological Fate of Chemicals, vol. 28, no. 7, pp. 766-771, 2000. 
[17] D.-W. Shang, Z.-Z. Wang, H.-T. Hu et al., "Effects of food and grapefruit juice on single-dosepharmacokinetics of blonanserin in healthy Chinese subjects," European Journal of Clinical Pharmacology, vol. 74, no. 1, pp. 61-67, 2018.

[18] M. T. San Miguel, J. A. Martínez, and E. Vargas, "Food-drug interactions in the summary of product characteristics of proprietary medicinal products," European Journal of Clinical Pharmacology, vol. 61, no. 2, pp. 77-83, 2005.

[19] L. Williams, J. A. Davis, and D. T. Lowenthal, "The influence of food on the absorption and metabolism of drugs," Medical Clinics of North America, vol. 77, no. 4, pp. 815-829, 1993.

[20] M. F. Paine, A. B. Criss, and P. B. Watkins, "Two major grapefruit juice components differ in time to onset of intestinal CYP3A4 inhibition," Journal of Pharmacology and Experimental Therapeutics, vol. 312, no. 3, pp. 1151-1160, 2005.

[21] N. Mazi-Kotwal and M. Seshadri, "Drug interactions with grapefruit juice," British Journal of Medical Practitioners, vol. 5, p. a538, 2012.

[22] D. G. Bailey, G. Dresser, and J. M. O. Arnold, "Grapefruit-medication interactions: forbidden fruit or avoidable consequences?" Canadian Medical Association Journal, vol. 185 , no. 4 , pp. 309-316, 2013.

[23] P. Paśko, T. Rodacki, R. Domagała-Rodacka, and D. Owczarek, "A short review of drug-food interactions of medicines treating overactive bladder syndrome," International Journal of Clinical Pharmacy, vol. 38, no. 6, pp. 13501356, 2016. 